\title{
Ceiling effect of clomiphene citrate on the testosterone to estradiol ratio in eugonadal infertile men
}

\author{
Yian Liao, Yi-Kai Chang, Shuo-Meng Wang, Hong-Chiang Chang $\bigodot^{*}$ \\ Department of Urology, National Taiwan University Hospital, Taipei, Taiwan \\ * changhong@ntu.edu.tw
}

\section{Abstract}

\section{Introduction}

The testosterone to estradiol ratio (T/E2 ratio) reportedly exerts a stronger effect on semen quality and sexual desire than does testosterone alone. Clomiphene citrate is a selective

\section{Gopen access}

Citation: Liao Y, Chang Y-K, Wang S-M, Chang H$C$ (2022) Ceiling effect of clomiphene citrate on the testosterone to estradiol ratio in eugonadal infertile men. PLoS ONE 17(1): e0262924. https://doi.org/ 10.1371/journal.pone.0262924

Editor: Joël R. Drevet, Universite Clermont Auvergne, FRANCE

Received: August 11, 2021

Accepted: January 7, 2022

Published: January 31, 2022

Peer Review History: PLOS recognizes the benefits of transparency in the peer review process; therefore, we enable the publication of all of the content of peer review and author responses alongside final, published articles. The editorial history of this article is available here: https://doi.org/10.1371/journal.pone.0262924

Copyright: @ 2022 Liao et al. This is an open access article distributed under the terms of the Creative Commons Attribution License, which permits unrestricted use, distribution, and reproduction in any medium, provided the original author and source are credited.

Data Availability Statement: All relevant data are within the manuscript.

Funding: The authors received no specific funding for this work. estrogen receptor modulator that has long been used as an empirical treatment option in the management of idiopathic oligozoospermia. Clomiphene may change the hypothalamuspituitary-gonad axis and result in the alteration of the T/E2 ratio. No reliable data are available regarding the change in the T/E2 ratio after clomiphene use in eugonadism.

\section{Methods}

This study included 24 male patients who were diagnosed with idiopathic infertility with eugonadism. They all received clomiphene citrate $(25 \mathrm{mg} /$ day $)$ as empirical treatment. Blood tests for serum testosterone, estradiol, prolactin, luteinizing hormone, and follicle stimulating hormone were performed before and after 4 weeks of clomiphene use. Paired ttests were used to evaluate the significance of the hormone level change.

\section{Results}

Overall, the patients' T/E2 ratio did not increase significantly after clomiphene use. In the subgroup analysis, the T/E2 ratio of patients with a baseline ratio of $<200$ increased significantly after clomiphene use.

\section{Conclusions}

Clomiphene citrate may significantly increase the T/E2 ratio in eugonadal men under the premise of its ceiling effect (T/E2 ratio <200), providing practitioners with guidance on the use of clomiphene in this demographic. 
Competing interests: The authors have declared that no competing interests exist.

Abbreviations: T/E2 ratio, Testosterone to Estradiol ratio; SERMs, Selective estrogen receptor modulators; GnRH, Gonadotropin-releasing hormone; FSH, Follicle-stimulating hormone; LH, Luteinizing hormone.

\section{Introduction}

Selective estrogen receptor modulators (SERMs) are drugs that act on estrogen receptors [1]. Such drugs can be divided into receptor agonists and antagonists. These drugs selectively act on specific organs, with effects differing by organs [1]. Clomiphene citrate is both a nonsteroidal antiestrogen drug and an SERM that competes with estradiol for estrogen receptors in the hypothalamus and blocks the normal negative feedback of circulating estradiol on the hypothalamus [2]. The production of gonadotroptin-releasing hormone (GnRH) may not be limited by estrogen; instead, the pituitary gland releases more follicle-stimulating hormone (FSH) and luteinizing hormone $(\mathrm{LH})$ and causes an increase in sperm and testosterone production by the testes [2]. High levels of intratesticular testosterone is a key factor in the nonconventional pathway of testosterone for spermatogenesis [3].

Abhyankar [4] revealed that the testosterone/estradiol (T/E2) ratio exerts a stronger effect on semen quality and sexual desire than did testosterone alone; the author concluded that a larger increase in the sperm concentration and total motility count was correlated with a larger increase in the posttreatment T/E2 ratio. A small population study by Shabsigh [5] also reported an increased T/E2 ratio after clomiphene use in patients with hypogonadism; the author concluded that low dose clomiphene citrate may improve the T/E2 ratio in men with hypogonadism. However, to our knowledge, no large study has been conducted on the T/E2 ratio change after clomiphene use in infertile patients with eugonadism. The aim of this preliminary study was to determine whether clomiphene citrate exerts an effect on the T/E2 ratio in infertile patients with eugonadism.

\section{Materials and methods}

This single-center, retrospective study was conducted in the Urology Department of \#\#\# from May 1, 2018, to May 31, 2019. Inclusion criteria were as follows: (1) being a man diagnosed with infertility; (2) taking clomiphene as testosterone restoration therapy; (3) accepting blood tests including those for prolactin, LH, FSH, testosterone, and estrogen; and (4) having an initial testosterone level within the normal range. Those who had undergone surgery of the testis or had received hormonal drugs that would affect the testosterone level (including dutasteride and leuprorelin) were excluded. Infertility was defined as failure to establish a clinical pregnancy after 12 months of regular and unprotected sexual intercourse. The normal range of the total testosterone level was defined as 240 to $870 \mathrm{ng} / \mathrm{dL}$.

The study protocol was approved by the Institutional Review Board of \#\#\#\# with relevant jurisdiction (IRB No. 201903111RIN). The necessity of informed consent was confirmed by the institutional review board.

Before receiving clomiphene citrate treatment, blood samples were examined to record baseline serum total testosterone, estradiol, LH, FSH, and prolactin levels. All patients received clomiphene citrate $25 \mathrm{mg}$ once a day for at least 1 month. Patients were followed up at 4 weeks after the treatment initiation to evaluate the treatment response. At the follow-up visit, the aforementioned serum levels were recorded to compare with those before clomiphene use. All hormone test(testosterone, estradiol, LH, FSH and prolactin) included in our study are sent to the central lab in "Department of Laboratory Medicine of National Taiwan University Hospital”. FSH, LH, E2 and prolactin were measured by using IMMULITE ${ }^{\circledR} 2000$ immunoassay system and Testosterone was measured by the ARCHITECT ${ }^{\circledR}$ 2nd Generation Testosterone assay which is a chemiluminescent microparticle immunoassay for the quantitative determination of testosterone. Simple statistical analysis (paired t-tests) was used to analyze hormone level changes resulting from clomiphene therapy. The primary outcome of our study was changes in the T/E2 ratio after the administration of clomiphene citrate in eugonadal men 
with infertility. Secondary outcomes included changes in other hormone levels (FSH, LH, and prolactin).

\section{Results}

In total, 22 men were retrospectively reviewed in this study. The average age of these patients was 40.9 (range: $31-48$ ) years, with 12 being older than 40 years. All patients were followed up in an outpatient clinic by one urologist. Most of these patients were healthy individuals seeking treatment for infertility; however, one had hypertension and ulcerative colitis, and another had liver cirrhosis, diabetes mellitus, and polyneuropathy.

The mean total testosterone level before treatment $(n=22)$ was $469 \pm 204$ (range: $212-947)$ $\mathrm{ng} / \mathrm{dL}$, and the mean estradiol level $(\mathrm{n}=21)$ was $3.819 \pm 1.312$ (range: $1.3-7.8) \mathrm{ng} / \mathrm{dL}$. The mean T/E2 ratio at the first visit $(\mathrm{n}=21)$ was $160 \pm 90$ (Table 1). The mean $\mathrm{LH}(\mathrm{n}=21)$ and FSH $(\mathrm{n}=22)$ levels were $4.89 \pm 3.05$ (range: $1.54-14.3) \mathrm{mIU} / \mathrm{mL}$ and $5.68 \pm 3.17$ (range: $1.59-$ $14.4) \mathrm{mIU} / \mathrm{mL}$, respectively. The mean prolactin level $(\mathrm{n}=21)$ was $6.80 \pm 3.32$ (range: 0.9 12.7) $\mathrm{ng} / \mathrm{mL}$ (Table 1).

The patients were re-evaluated approximately 4 weeks after initiating therapy with $25 \mathrm{mg}$ of oral clomiphene citrate once a day. A significant increase was noted in the mean total testosterone level $(\mathrm{n}=22)$ to $935 \pm 349$ (range: $285-1916) \mathrm{ng} / \mathrm{dL}$, representing an increase of $99.2 \%$ $(\mathrm{P}<0.001)$. The mean estradiol level $(\mathrm{n}=21)$ increased significantly to $6.605 \pm 3.091$ (range: $2.57-1.30) \mathrm{ng} / \mathrm{dL}$, representing a rise of $80.8 \%(\mathrm{P}<0.001)$. The T/E2 ratio also increased from $160 \pm 90$ to $180 \pm 60$, a rise of $12.5 \%$; however, the difference was not significant $(\mathrm{P}=0.302$; Table 1). The posttreatment mean LH $(\mathrm{n}=21)$ and FSH $(\mathrm{n}=22)$ levels increased significantly to $10.90 \pm 5.92$ (range: $2.93-22.2) \mathrm{mIU} / \mathrm{mL}(\mathrm{P}<0.001)$ and $11.43 \pm 7.86$ (range: $4.25-36.9)$ $\mathrm{mIU} / \mathrm{mL}(\mathrm{P}=0.002)$, representing an increase of $123.1 \%$ and $101.3 \%$, respectively. The posttreatment mean prolactin level $(\mathrm{n}=21)$ decreased to $5.77 \pm 2.49($ range: $2.84-12.20) \mathrm{ng} / \mathrm{mL}$; this $15.1 \%$ decrease, however, did not reach significance $(\mathrm{P}=0.297$; Table 1$)$.

The 21 patients included were further analyzed according to the baseline T/E2 ratio. Four patients had a baseline T/E2 ratio of $<100$. Their mean T/E2 ratio increased significantly from $070 \pm 10$ to $110 \pm 20$ after clomiphene use, representing an increase of $57.1 \%(P=0.006)$. Twelve patients had a baseline T/E2 ratio of $<150$. Their mean T/E2 ratio significantly increased from $090 \pm 30$ to $130 \pm 40$ after clomiphene use, which is an increase of $44.4 \%$ $(P=0.006)$. Fifteen patients had a baseline T/E2 ratio of $<200$. Their mean $T / E 2$ ratio significantly increased from $120 \pm 40$ to $150 \pm 50$ after clomiphene use, representing an increase of $25.0 \%(\mathrm{P}=0.0017)$. The $\mathrm{T} / \mathrm{E} 2$ ratio of the five patients with a baseline $\mathrm{T} / \mathrm{E} 2$ ratio $<250$

Table 1. Endocrinology data at baseline and 4 weeks after initiating clomiphene treatment.

\begin{tabular}{l|l|l|l|l|l}
\hline Hormone (Conc.) & Number of cases & Baseline $^{\mathbf{a}}$ & Post treatment $^{\mathbf{b}}$ & Clomiphene effect $^{\text {P value }}$ \\
\hline Testosterone(ng/dL) & 22 & $469 \pm 204$ & $935 \pm 349^{*}$ & $\uparrow 99.2 \%$ & $<0.001$ \\
\hline Estradiol (ng/dL) & 21 & $3.819 \pm 1.312$ & $6.605 \pm 3.091^{*}$ & $\uparrow 80.8 \%$ & $<0.001$ \\
\hline T/E2 ratio & 21 & $160 \pm 90$ & $180 \pm 60$ & $\uparrow 12.5 \%$ & 0.302 \\
\hline LH $(\mathrm{mIU} / \mathrm{mL})$ & 21 & $4.89 \pm 3.05$ & $10.90 \pm 5.92^{*}$ & $\uparrow 123.1 \%$ & $<0.001$ \\
\hline FSH $(\mathrm{mIU} / \mathrm{mL})$ & 22 & $5.68 \pm 3.17$ & $11.43 \pm 7.86^{*}$ & $\uparrow 101.3 \%$ & 0.002 \\
\hline Prolactin $(\mathrm{ng} / \mathrm{mL})$ & 21 & $6.80 \pm 3.32$ & $5.77 \pm 2.49$ & $\downarrow 15.1 \%$ & 0.297 \\
\hline
\end{tabular}

Values are presented as the mean \pm standard deviation.

*Versus baseline data $(\mathrm{p}<0.05)$.

${ }^{a}$ Baseline hormone level before Clomiphene use.

${ }^{\mathrm{b}}$ Hormone level after Clomiphene use.

https://doi.org/10.1371/journal.pone.0262924.t001 
increased from $120 \pm 50$ to $160 \pm 50$; however, the difference was not significant $(\mathrm{P}=0.09)$, which is similar to the result in the group with all patients included $(\mathrm{n}=21, \mathrm{P}=0.302$;

Table 2).

\section{Discussion}

Clomiphene citrate, an SERM, is a nonsteroidal antiestrogen drug that has empirically been used in the management of idiopathic oligospermia. The drug competes with estradiol for estrogen receptors in the hypothalamus and blocks the normal negative feedback of circulating estradiol on the hypothalamus [6, 7]. Under clomiphene therapy, the amplitude of GnRH pulses increases, stimulating the pituitary gland to produce more FSH and LH. As a result, testicular total testosterone also increases $[6,8-10]$. When used to treat male infertility, clomiphene is well tolerated with no identified serious adverse effects [11-13].

Few studies have investigated the relationship between clomiphene citrate use and the T/E ratio. Shabsigh [4] recruited 36 Caucasian men with hypogonadism, defined as having a serum total testosterone level of $<300 \mathrm{ng} / \mathrm{dL}$. Each patient was treated with a daily dose of $25 \mathrm{mg}$ clomiphene citrate. The serum levels of total testosterone and estradiol were recorded at baseline and follow-up visits. By the first follow-up visit (at 4-6 weeks), the mean total testosterone level had increased significantly $(\mathrm{P}<0.00001)$. Moreover, the T/E ratio improved from 8.7 to $14.2(\mathrm{P}<0.001)$. Thus, the T/E2 ratio of patients with hypogonadism increased after clomiphene use. No further research on clomiphene use and the testosterone to estradiaol ratio in eugonadal patients has been conducted, prompting the current study.

In our study, we observed a significant increase in the mean total testosterone level, with an increase of $99.2 \%(\mathrm{P}<0.001)$. The mean estradiol level also increased significantly, with a rise of $80.8 \%$ ( $\mathrm{P}<0.001)$. These results are similar to those of patients with hypogonadism in the aforementioned study [4] who took clomiphene citrate. As for other hormone levels, the mean FSH and LH levels increased significantly after clomiphene treatment, with a rise of $101.3 \%$ $(\mathrm{P}=0.002)$ and $123.1 \%(\mathrm{P}<0.001)$, respectively. Because clomiphene citrate competes with estradiol for estrogen receptors in the hypothalamus, it blocks the normal negative feedback of circulating estradiol in the hypothalamus. As a result, LH and FSH levels would increase, which is consistent with our results.

Regarding the T/E2 ratio, compared with the T/E2 ratio in the general male population, that of patients enrolled in our study was relatively low. Gong [14] enrolled 337 patients in a single center as the control group to study the correlation between the T/E2 ratio and cardiovascular events, revealing the normal range of the T/E2 ratio to be $190 \pm 60$. In our study, the

Table 2. T/E2 ratio of men with a lower baseline ratio $(<0.20)$ increased significantly after clomiphene treatment.

\begin{tabular}{l|l|l|l|l|l}
\hline Upper limit of T/E2 & Number of cases & Baseline $^{\mathbf{a}}$ & Post treatment $^{\mathbf{b}}$ & Clomiphene effect & P value $^{-}$ \\
\hline Any & 21 & $160 \pm 90$ & $0.18 \pm 0.06$ & $\uparrow 12.5 \%$ & 0.302 \\
\hline$<0.25$ & 17 & $120 \pm 50$ & $160 \pm 50$ & $\uparrow 33.3 \%$ & 0.09 \\
\hline$<0.20$ & 15 & $120 \pm 40$ & $150 \pm 50^{*}$ & $\uparrow 25.0 \%$ & 0.017 \\
\hline$<0.15$ & 12 & $90 \pm 30$ & $130 \pm 40^{*}$ & $\uparrow 44.4 \%$ & 0.006 \\
\hline$<0.10$ & 4 & $70 \pm 10$ & $110 \pm 20^{*}$ & $\uparrow 57.1 \%$ & 0.006 \\
\hline
\end{tabular}

Values are presented as the mean \pm standard deviation.

${ }^{*}$ Versus baseline data $(\mathrm{p}<0.05)$.

${ }^{a}$ Baseline T/E2 level before clomiphene use.

${ }^{\mathrm{b}} \mathrm{T} / \mathrm{E} 2$ after clomiphene use.

https://doi.org/10.1371/journal.pone.0262924.t002 
mean baseline T/E2 ratio was $160 \pm 90$. When including all patients, we noted an increase of $6.25 \%$ in the ratio, but the difference was not significant. We obtained different results when setting an upper limit of the T/E2 ratio. The mean T/E2 ratio increased significantly (57.1\%) after clomiphene use if only patients with a T/E2 ratio of $<100$ were included. A significant increase in the T/E2 ratio after clomiphene use was also noted in those with a T/E2 ratio of $<200$. After slightly increasing the upper limit to a T/E2 ratio of $<250$, we still noted an increase of $33.3 \%$ in the T/E2 ratio; however, the difference was not significant. Therefore, we suggest ceiling effects for increasing the T/E2 ratio; in the current study, the ceiling effect was set at a T/E2 ratio of $<200$. This result suggests that using clomiphene in infertile men with eugonadism whose $\mathrm{T} / \mathrm{E}$ ratio is $>200$ is not advisable.

This study has some limitations. Only 24 patients were included; thus, the sample was relatively small. Moreover, because this was a retrospective study, the exposure method could not be controlled, potentially resulting in variable clomiphene citrate dosage and frequency. Possible factors that may affect total testosterone and estradiol level, such as BMI level, waistline and testicular volume, were also not included. Future studies should prospectively include these parameters for analysis to confirm the T/E2 ratio changeafter clomiphene citrate use in infertile men with eugonadism.

\section{Conclusion}

Clomiphene citrate may significantly increase the T/E2 ratio in eugonadal infertile men under the premise of its ceiling effect $(\mathrm{T} / \mathrm{E} 2$ ratio $<200)$, providing useful guidance for the use of clomiphene in this group of patients. Further investigations, especially those with a larger sample size, are required to confirm the results.

\section{Acknowledgments}

The authors also wish to thank all patients participated in this study.

\section{Author Contributions}

Conceptualization: Yian Liao, Shuo-Meng Wang, Hong-Chiang Chang.

Data curation: Yian Liao.

Formal analysis: Yian Liao.

Investigation: Yian Liao.

Methodology: Yian Liao.

Resources: Yian Liao.

Software: Yian Liao.

Supervision: Yi-Kai Chang, Shuo-Meng Wang, Hong-Chiang Chang.

Writing - original draft: Yian Liao.

Writing - review \& editing: Yian Liao, Hong-Chiang Chang.

\section{References}

1. Chua M.E., et al. Revisiting oestrogen antagonists (clomiphene or tamoxifen) as medical empiric therapy for idiopathic male infertility: a meta-analysis. Andrology, 2013. 1: 749. https://doi.org/10.1111/j. 2047-2927.2013.00107.x PMID: 23970453 
2. Ribeiro R.S., et al. Clomiphene fails to revert hypogonadism in most male patients with conventionally treated nonfunctioning pituitary adenomas. Arq Bras Endocrinol Metabol, 2011. 55: 266. https://doi.org/ 10.1590/s0004-27302011000400005 PMID: 21779629

3. Hussein A., et al. Clomiphene administration for cases of nonobstructive azoospermia: a multicenter study. J Androl, 2005. 26: 787. https://doi.org/10.2164/jandrol.04180 PMID: 16291975

4. Abhyankar N., Shoshany O., Niederberger C. Testosterone to estradiol ratio correlates with sperm concentration improvement in hypogonadal oligozoosermic patients treated with anastrozole. 106(3): e239-e240 - September 2016.

5. Ahmad Shabsigh MD, Young Kang MD, Ridwan Shabsign MD. Clomiphene Citrate Effects on Testosterone/Estrogen Ratio in Male Hypogonadism. J Sex Med 2005; 2:716-721. https://doi.org/10.1111/j. 1743-6109.2005.00075.x PMID: 16422830

6. Goldstein SR, Siddhanti S, Ciaccia AV, Plouffe L Jr. A pharmacological review of selective oestrogen receptor modulators. Hum Reprod Update 2000; 6:212-24. https://doi.org/10.1093/humupd/6.3.212 PMID: 10874566

7. Riggs BL, Hartmann LC. Selective estrogen-receptor modulators-mechanisms of action and application to clinical practice. N Engl J Med 2003.

8. Tan RS, Vasudevan D. Use of clomiphene citrate to reverse premature andropause secondary to steroid abuse. Fertil Steril 2003; 79:203-5. https://doi.org/10.1016/s0015-0282(02)04550-8 PMID: 12524089

9. Guay AT, Bansal S, Heatley GJ. Effect of raising endogenous testosterone levels in impotent men with secondary hypogonadism: Double blind placebo-controlled trial with clomiphene citrate. J Clin Endocrinol Metab 1995; 80:3546-52. https://doi.org/10.1210/jcem.80.12.8530597 PMID: 8530597

10. Guay AT, Jacobson J, Perez JB, Hodge MB, Velasquez E. Clomiphene increases free testosterone levels in men with both secondary hypogonadism and erectile dysfunction: Who does and does not benefit? Inter J Impot Res 2003; 15:156-65.

11. Willets AE, Corbo JM, Brown JN. Clomiphene for the treatment of male infertility. Reprod Sci. 2013; 20:739-44. https://doi.org/10.1177/1933719112466304 PMID: 23202725

12. Moskovic DJ, Katz DJ, Akhavan A, Park K, Mulhall JP. Clomiphene citrate is safe and effective for longterm management of hypogonadism. BJU Int. 2012; 110:1524-8. https://doi.org/10.1111/j.1464-410X. 2012.10968.x PMID: 22458540

13. Taylor F, Levine L. Clomiphene citrate and testosterone gel replacement therapy for male hypogonadism: efficacy and treatment cost. J Sex Med 2010; 7: 269-76. https://doi.org/10.1111/j.1743-6109. 2009.01454.x PMID: 19694928

14. Gong Yanping, Xiao Haiying, Li Chunlin, Bai Jie, Cheng Xiaoling. Elevated T/E2 Ratio Is Associated with an Increased Risk of Cerebrovascular Disease in Elderly Men, 2013 Apr 24; 8(4):e61598. https:// doi.org/10.1371/journal.pone.0061598 PMID: 23637864 